Authors has nothing to disclose with regard to commercial support.

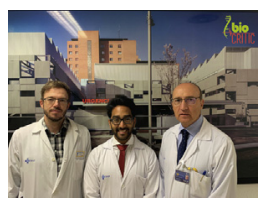

\section{ACUTE KIDNEY INJURY AFTER ADULT CARDIAC SURGERY: TRYING TO FIND THE MAGIC GUN}

\section{To the Editor:}

We highly appreciate the commentary by Montisci and colleagues, " "Commentary: The Lack of a Magic Bullet," regarding our recently published article. ${ }^{2}$ Montisci and colleagues ${ }^{1}$ raised some points that in their view could affect the clinical relevance of the study. We are happy to discuss these particular issues, and we seize the opportunity of this letter to go more deeply into details.

Undoubtedly, acute kidney injury is a deadly complication after cardiac surgery. ${ }^{3,4}$ A drop in the kidney oxygen saturation $\left(\mathrm{kSO}_{2}\right)$ to less than $65 \%$ and a decline of more than $20 \%$ from the baseline value during the postoperative stage were identified as independent predictors of cardiac surgery-associated acute kidney injury (CSA-AKI). Regarding the variability in threshold desaturation definitions, these findings were determined from both absolute and patient-specific $\mathrm{kSO}_{2}$ baseline values. Indeed, we agree that to draw conclusions from absolute threshold values might be relatively difficult, because normal $\mathrm{kSO}_{2}$ values vary from one patient to another. This is not the case for declines from patient-specific baseline values, however, which are consistent results that do not change regardless of any threshold value and therefore can be applied to any population.

Near-infrared spectroscopic measurements provide a time-limited window before irreversible organ failure occurs. We are convinced, however, that instead of seeking a "window for intervention," it is much more worthwhile to look for a "window for prevention," taking into account that the prevention is the criterion standard management of CSA-AKI, rather than its treatment. This was the primary reason that our efforts were directed toward the early recognition and the prevention of CSA-AKI, without the introduction of any external measure that might alter our

\footnotetext{
The Editor welcomes submissions for possible publication in the Letters to the Editor section that consist of commentary on an article published in the Journal or other relevant issues. Authors should: • Include no more than 500 words of text, three authors, and five references. • Type with double-spacing. • See http://jtcs.ctsnetjournals.org/ misc/ifora.shtml for detailed submission instructions. • Submit the letter electronically via jtcvs.editorialmanager.com. Letters commenting on an article published in the JTCVS will be considered if they are received within 6 weeks of the time the article was published. Authors of the article being commented on will be given an opportunity of offer a timely response ( 2 weeks) to the letter. Authors of letters will be notified that the letter has been received. Unpublished letters cannot be returned.
}

results. Ranucci and associates ${ }^{5}$ showed that the application of goal-directed perfusion strategy to maintain oxygen delivery during cardiopulmonary bypass greater than $280 \mathrm{~mL} \cdot \min ^{-1} \cdot \mathrm{m}^{-2}$ reduces the appearance of mild stages of CSA-AKI. As such, it is also a strategy aiming to prevent CSA-AKI.

Undeniably, a timely intervention requires a prompt recognition of potential CSA-AKI. An opportune recognition is thus crucial for an optimal treatment. Given the scarcity of evidence to establish an appropriate treatment to $\mathrm{kSO}_{2}$ desaturations, no interventions were introduced. Certainly, further clinical trials should be conducted to establish and validate goal-directed therapies enhancing $\mathrm{kSO}_{2}$, just like the already accepted protocols to reverse brain oxygen desaturations. ${ }^{6}$

Overall, on the basis of the complex pathogenesis of CSA-AKI, it is unlikely that its incidence can be significantly reduced by any single intervention. ${ }^{7}$ Just as contributing factors working in concert lead to this complication, the prevention and treatment of CSA-AKI require a multimodal approach in which not only the patient's underlying diseases or the knock-on effects of the cardiac surgical procedure itself must be taken into account, but also the altogether postoperative factors that still contribute to its appearance. Measurement of $\mathrm{kSO}_{2}$ seems to be a promising tool, at least in the fight for early recognition. It thus might be helpful to prevent postoperative CSA-AKI. Doubtless, before using the magic bullet, we need to find the "right weapon."

$$
\begin{array}{r}
\text { Christian Ortega-Loubon, MD, MEd, PhD } \\
\text { Pablo Jorge-Monjas, MD, PhD } \\
\text { Eduardo Tamayo, MD, PhD }{ }^{b, c} \\
{ }^{b} \text { Department of Cardiac Surgery } \\
\text { Clinic University Hospital of Valladolid } \\
\text { Valladolid, Spain } \\
{ }^{c} \text { Anesthesiology and Critical Care } \\
\text { Clinic University Hospital of Valladolid } \\
\text { Valladolid, Spain } \\
{ }^{b} \text { BioCritic }
\end{array}
$$

Group for Biomedical Research in Critical Care Medicine

\section{References}

1. Montisci A, Travaglini S, Miceli A. Commentary: the lack of a magic bullet. $J$ Thorac Cardiovasc Surg. 2019;157:2352-3.

2. Ortega-Loubon C, Fernández-Molina M, Fierro I, Jorge-Monjas P, Carrascal Y Gómez-Herreras JI, et al. Postoperative kidney oxygen saturation as a novel marker for acute kidney injury after adult cardiac surgery. J Thorac Cardiovasc Surg. 2019;157:2340-51.e3.

3. Ortega-Loubon C, Fernández-Molina M, Jorge-Monjas P, Fierro I, HerreraCalvo G, Tamayo E. The relevance of renal oxygen saturation over other markers in cardiac surgery-associated acute kidney injury. J Cardiothorac Vasc Anesth. 2019;33:2622-3.

4. Ortega-Loubon C, Fernández-Molina M, Pañeda-Delgado L, Jorge-Monjas P Carrascal Y. Predictors of postoperative acute kidney injury after coronary artery bypass graft surgery. Braz J Cardiovasc Surg. 2018;33:323-9. 
5. Ranucci M, Johnson I, Willcox T, Baker RA, Boer C, Baumann A, et al. Goal-directed perfusion to reduce acute kidney injury: a randomized trial J Thorac Cardiovasc Surg. 2018;156:1918-27.e2.

6. Deschamps A, Hall R, Grocott H, Mazer CD, Choi PT, Turgeon AF, et al; Canadian Perioperative Anesthesia Clinical Trials Group. Cerebral oximetry monitoring to maintain normal cerebral oxygen saturation during high-risk cardiac surgery: a randomized controlled feasibility trial. Anesthesiology. 2016;124: 826-36.

7. Ortega-Loubon C, Fernández-Molina M, Carrascal-Hinojal Y, Fulquet-Carreras E. Cardiac surgery-associated acute kidney injury. Ann Card Anaesth. 2016;19: $687-98$

https://doi.org/10.1016/j.jtcvs.2019.05.056

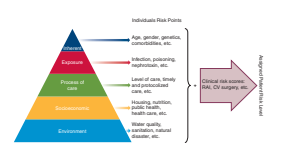

ACUTE KIDEY INJURY RISKS DURING CARDIAC OPERATIONS ARE TOO NUMEROUS TO COUNT? COULD

A SINGLE ACTIONABLE VARIABLE BE THE ANSWER?

Reply to the Editor:

An interesting aspect of articles that appear in the Journal of Thoracic and Cardiovascular Surgery is the dialog created by many of the articles and actually published along with the main research articles. Readers must realize that the Editor emphasizes these dialogs and nearly every article has an associated commentary and/or expert opinion about article findings. The discussions surrounding many of the Journal articles and the associated editorial comments often serve to elaborate and delve into nuances of article findings.

Perhaps more importantly, these discussions can stimulate new information, and can expand on resarch findings. An example of this is the series of articles generated by the study conducted by Ortgea-Loubon and colleagues $^{1}$ that deals with measurement of kidney oxygen saturation (kSo2) as a potentially actionable biomarker of acute kidney injury (AKI) after cardiac operations. The back-and-forth articles stemming from the original article both amplify the original findings of the sentinel article and clarify nuances and alternative findings of importance. ${ }^{2,3}$ This type of dialog is a tribute to the Journal, and whether readers realize it or not, this type of expansion and the extent of introspection around published original research is nearly exclusive to our Journal.

Over the past year and a half, some things have been described in the literature that influence AKI (see Table 1). With the abundance of complicating factors that can alter renal function during cardiac procedures in adults and children, surely it must be simplistic to focus on a single indicator like $\mathrm{kSO} 2$ as an actionable variable that may improve AKI risk after cardiac operations. Ortega-Loubon and colleagues ${ }^{1}$ suggest, but do not prove, that alterations that improve $\mathrm{kSo} 2$ may lessen risk of AKI after operations
TABLE 1. Recent evidence base for prevention of acute kidney injury (AKI) associated with cardiac operations

Things that may reduce/improve AKI risk after cardiac operations Cytochrome-eicosanoid inhibition and $\mathrm{AKI}^{4}$

High estimated pulmonary artery systolic pressure to predict acute kidney injury

Enteral flavone glycoside reduces cardiac surgery-Associated AKI in rats ${ }^{6}$

$\mathrm{N}$-acetyl cysteine to prevent postoperative $\mathrm{AKI}$ in preexistingrenal-failure

Naturetic peptide is best drug with evidence for prevention of AKI

Low-dose doxycycline in rats is protective against $\mathrm{AKI}^{8}$

Early peritoneal dialysis to prevent AKI in neonates ${ }^{9}$

Things that do not work for AKI prevention

Mannitol not considered an evidence-based intervention to limit $\mathrm{AKI}^{10}$

Corticosteroid treatment in neonates undergoing cardiac surgery did not reduce $\mathrm{AKI}^{1}$

$\mathrm{N}$-acetylcysteine not helpful to reduce AKI (meta-analysis) ${ }^{12}$ Allogeneic mesenchymal stem cells ${ }^{13}$

Things with uncertain or conflicting evidence but being studied Dexmedetomidine and acetaminophen ${ }^{14-16}$

Slidenafil for AKI (randomized controlled trial) ${ }^{17}$

Intra-aortic balloon ${ }^{18}$

Vascular endothelial integrity ${ }^{19}$

Remote ischemic preconditioning ${ }^{20,21}$

Dexmedetomidine and acetaminophen ${ }^{14-16}$

Things that may worsen AKI risk during cardiac procedures

Perioperative statin therapy (but not preoperative only therapy) increases AKI risk ${ }^{22}$

Fibrinogen prophylaxis during heart transplant ${ }^{2}$

Advanced age $\geq 80 \mathrm{y}^{24}$

Severe bleeding ${ }^{25}$

and improve functional outcomes. Believe me, I hope they are right, but a lot more work (eg, randomized trials and measurements of covariates) needs to be done to establish $\mathrm{kSo} 2$ as an actionable variable that can limit AKI after cardiac operations. I welcome further dialog and even more well-designed comparative studies that prove the value of $\mathrm{kSo} 2$.

Victor A. Ferraris, $M D, P h D$

Department of Surgery University of Kentucky

Lexington, Ky

\section{References}

1. Ortega-Loubon C, Fernandez-Molina M, Fierro I, Jorge-Monjas P, Carrascal Y, Gómez-Herreras JI, et al. Postoperative kidney oxygen saturation as a novel marker for acute kidney injury after adult cardiac surgery. $J$ Thorac Cardiovasc Surg. 2019;157:2340-51.

2. Ferraris VA. Perfusion-induced acute kidney injury: critiques that do not roll off the tongues of thoracic surgeons. J Thorac Cardiovasc Surg. 2019;157: e279-80. 